\title{
Splenic volume and hematological parameters in extrahepatic portal vein obstruction
}

\author{
Viroj Wiwanitkit
}

Accepted: 20 April 2011/Published online: 6 May 2011

(C) Springer-Verlag 2011

Editor, I read the recent publication on correlation of splenic volume with hematological parameters, splenic vein diameter, portal pressure and grade of varices in extrahepatic portal vein obstruction with a great interest [1]. Singh et al. [1] found that "larger splenic volumes were associated with lower hemoglobin and platelet counts and significantly lower total leukocyte counts." I agree with the finding but I would like to draw attention to some facts. First, there might be some confounding factors that can affect the studied parameter. The possible congenital concurrent hematolological disorders especially for thalassemia and hemoglobinopathies should be kept in mind.
These hematological disorders can significantly affect both splenic structure as well as hematological parameters.

\section{References}

1. Singh IK, Bhatnagar V, Gupta AK, Seith K (2001) Correlation of splenic volume with hematological parameters, splenic vein diameter, portal pressure and grade of varices in extrahepatic portal vein obstruction in children. Ped Surg Int 27:467-471

V. Wiwanitkit $(\bowtie)$

Wiwanitkit House, Bangkhae, Bangkok 10160, Thailand

e-mail:wviroj@yahoo.com 